\title{
Covid-19 Lockdown and Changes of Air Quality in the Most Polluted City of Bangladesh
}

\author{
M. N. Ferdous, M. A. Islam*", P. Chakrabortty, S. Kabir \\ Department of Environmental Science and Disaster Management, Bangabandhu Sheikh Mujibur \\ Rahman Science \& Technology University, Gopalganj-8100, Bangladesh
}

Received 10 December 2020, accepted in final revised form 9 June 2021

\begin{abstract}
Air pollution is now a serious issue all over the world. Especially, people of developing countries are seriously affected by air pollution because, like other pollution, air pollution is not given importance. Due to the covid-19 lockdown, pollution is reduced, and as expected, the air quality of Dhaka city has improved. Daily AQI data was collected for the months of April, May and June (2020) and compared with the last six years of data for these months respectively. It was found that the mean AQI of Dhaka city in April, May, and June lower than the last six years in the same period. The mean AQI decreased $43.52 \%, 22.37 \%, 9,82$ $\%, 16.38 \%, 41.43 \%, 34.16 \%$ in April when compared with April 2014-2019 respectively and the mean AQI decreased $33.69 \%, 37.97 \%, 39.25 \%, 36.81 \%, 45.59 \%, 44.15 \%$ in May when compared with May 2014-2019 respectively. The mean AQI decreased $26.48 \%$, $11.40 \%, 8.28 \%, 30.61 \%, 36.37 \%$ and increase $3.07 \%$ in June (2020) when it compared with June 2014-2019 respectively. This study includes the statistical examination of air quality before and at the time of covid-19 lockdown in Dhaka city.
\end{abstract}

Keywords: Covid-19 (Coronavirus); AQI; CASE; BNAAQS.

() 2021 JSR Publications. ISSN: 2070-0237 (Print); 2070-0245 (Online). All rights reserved.

doi: http://dx.doi.org/10.3329/jsr.v13i3.50647 J. Sci. Res. 13 (3), 707-714 (2021)

\section{Introduction}

Air pollution is now a growing concern for all countries in the world, especially for developing countries, like Bangladesh [1]. Air pollution is found in the top ten killers in the whole world and in the sixth position in south Asia. According to WHO, $80 \%$ of the population living in the urban region do not meet the standard air quality set by WHO. "In 2018" $97 \%$ of cities of middle-low-income countries and $49 \%$ in high-income countries crossed the limit of WHO standard. Every year around 4.2 million people die worldwide due to air pollution [2-4]. About 15,000 people died due to air pollution-related diseases. And Dhaka city of Bangladesh is already marked as a polluted for human. Bangladesh is a developing country and due to the rapid growth of industrialization and urbanization environment of Bangladesh is not like developed countries [5]. This situation continued

* Corresponding author: aminul.aim.25@gmail.com 
until the national authority of Bangladesh assigned lockdown due to the Covid-19 pandemic. Recent studies on environmental pollution, especially on-air pollution, show that the air quality of different cities in the world such as Brazil, China, Spain, Morocco, and India has improved. And the concentration of $\mathrm{PM}_{2.5}, \mathrm{PM}_{10}, \mathrm{SO}_{2}, \mathrm{CO}$, and $\mathrm{NO}_{2}$ reduced significantly in these cities [1].

\section{Materials and Methods}

Dhaka (Fig. 1) is the largest city and also the capital of Bangladesh. The location of this city is between $23^{\circ} 53^{\prime}$ and $24^{\circ} 06^{\prime}$ North latitudes and in the middle of $90^{\circ} 01^{\prime}$ and $90^{\circ} 37^{\prime}$ East longitudes [6]. Around $80 \%$ of the garment industries of Bangladesh are situated in her capital. A huge number of vehicles are also found in this city for the movement of a large population. In the last few years, this city has been marked as the most polluted by air quality due to this [7].

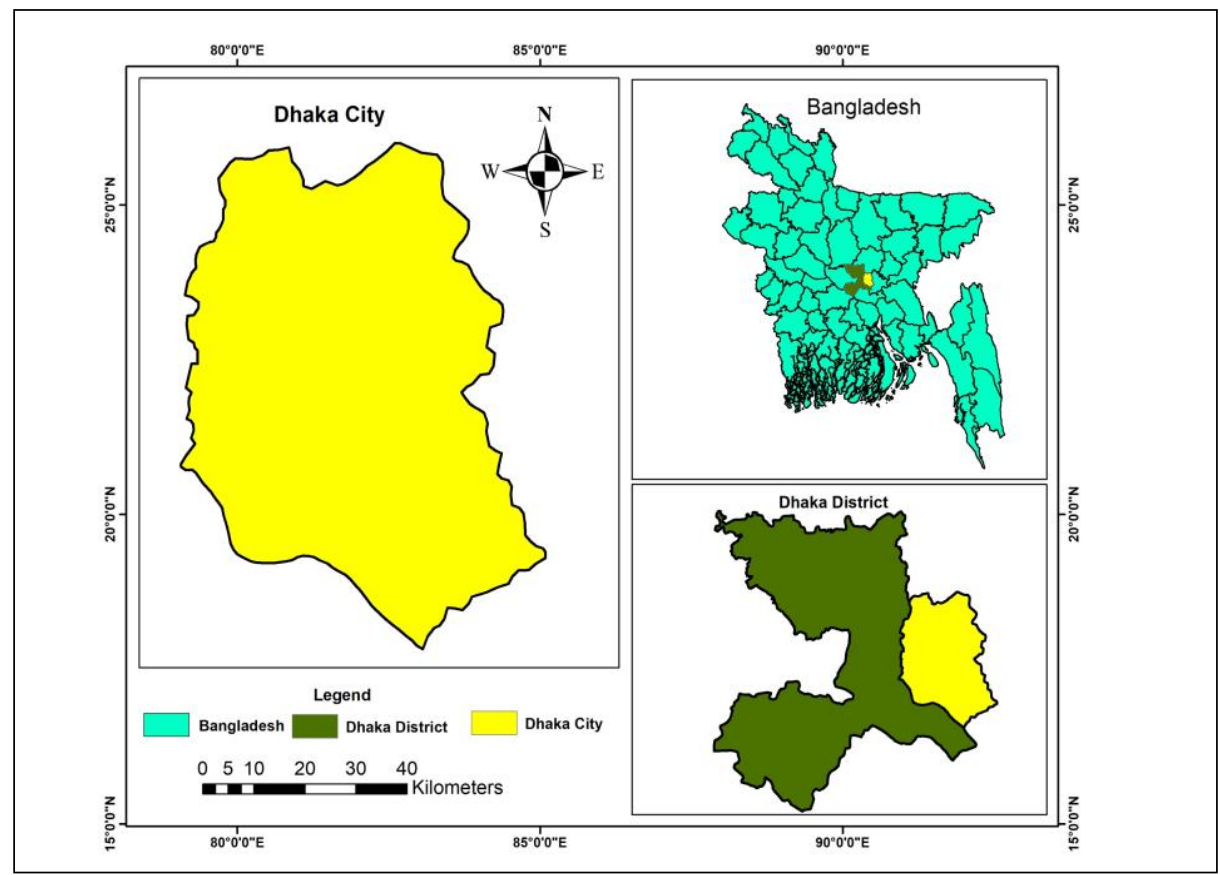

Fig. 1. Dhaka city study area.

Air quality analysis in Dhaka city from 2014 to 2020 is covered in this study [8]. The period of this study was from the $1^{\text {st }}$ day of April to $30^{\text {th }}$ June for each year. Daily AQI data was collected from the clean air and sustainable environment project [7,9]. Daily AQI was analyzed by ggplot2 package (version 3.3.1) in RStudio software (version 1.3.959.0) which is an IDE (Integrated Development Environment) for R programing language. It uses $\mathrm{R}$ script for graphics and statistical computing. Descriptive analysis is 
used for daily AQI analysis [10]. The correlations and linear regression of this study were analyzed by Microsoft Excel (2016).

\section{Results and Discussion}

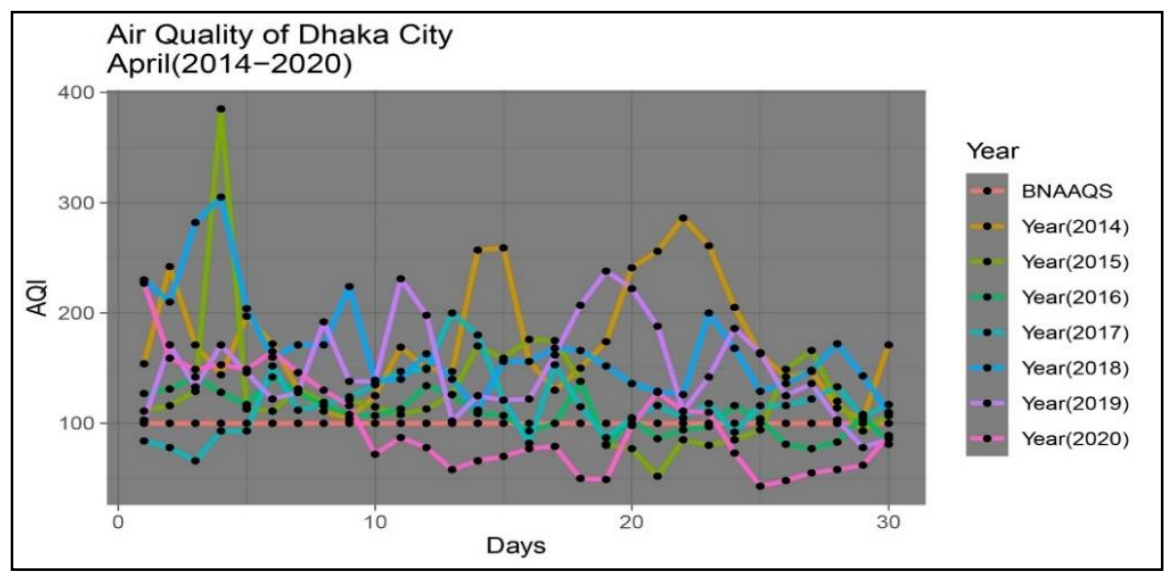

Fig. 2. Air quality of Dhaka city April (2014-2020).

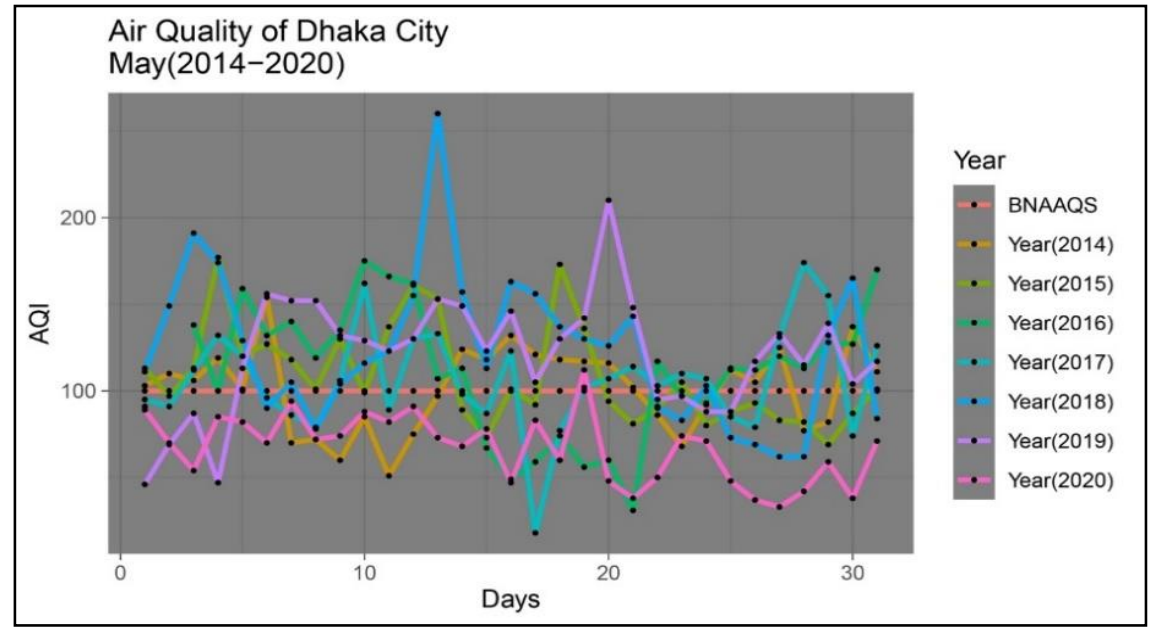

Fig. 3. Air quality of Dhaka city May (2014-2020).

Figs. (2-4) display the daily variation of AQI in Dhaka city [11]. When we compared Figs. (2-4), it was found that daily AQI in June (2020) was more than in April (2020) and May (2020) [7]. However, significant perfection in daily air quality is observed from April to May (2020) during Covid-19 (Coronavirus) lockdown is much better than in other years (2014-2019) [11]. Fig. 2 shows that the first 10 days of April (2020) cross the satisfactory limit, but most days don't cross the limit. But the AQI from (2014-2019) exceeds the limit. Fig. 3 shows that the air quality in May (2020) is below the limit, which 
is good for the people [1]. Fig. 4 shows that most days don't cross the standard limit. Maximum and minimum daily AQI values (227-43) in April (2020) and (112-33) in May (2020), and (154-22) in June [12]. In the South Asian region, air quality has also improved and brought positive outcomes. As expected, a positive impact is also found on the air quality of Dhaka city, shown in Figs. (2-4) due to covid-19 lockdown [13].

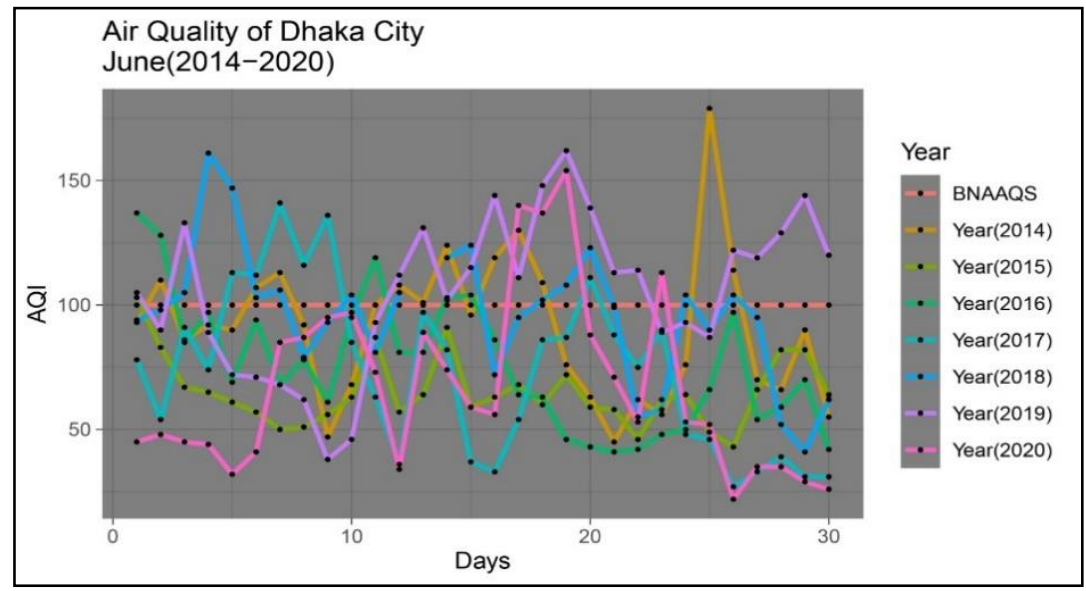

Fig. 4. Air quality of Dhaka city June (2014-2020).

Table 1. Descriptive analysis of air quality index of Dhaka city.

\begin{tabular}{lllllllllllllllllll}
\hline \multicolumn{1}{c}{ April } & \multicolumn{1}{c}{ May } & \multicolumn{4}{c}{ June } \\
\hline Year & Max & Min & Mean & S. D & CV & Max & Min & Mean & S. D & CV & Max & Min & Mean S. D & CV \\
\hline 2014 & 286 & 104 & 174.4 & 52.70 & 30.21 & 154 & 51 & 101.5 & 24.19 & 23.84 & 179 & 45 & 91.23 & 28.68 & 31.44 \\
2015 & 385 & 52 & 126.83 & 57.71 & 45.50 & 177 & 69 & 108.5 & 28.69 & 26.45 & 103 & 43 & 65.07 & 13.75 & 21.13 \\
2016 & 142 & 77 & 109.23 & 19.51 & 17.86 & 175 & 31 & 110.8 & 37.95 & 34.26 & 137 & 41 & 75.70 & 26.34 & 34.80 \\
2017 & 200 & 66 & 117.8 & 28.66 & 25.17 & 174 & 18 & 106.5 & 29.92 & 28.09 & 141 & 27 & 73.13 & 33.15 & 45.33 \\
2018 & 305 & 110 & 168.2 & 45.60 & 27.11 & 260 & 62 & 123.7 & 43.03 & 34.79 & 161 & 41 & 95.83 & 26.69 & 27.85 \\
2019 & 238 & 78 & 149.6 & 42.86 & 28.65 & 210 & 46 & 120.5 & 33.94 & 28.17 & 162 & 38 & 105.4 & 30.60 & 29.04 \\
2020 & 227 & 43 & 98.5 & 45.11 & 45.80 & 112 & 33 & 67.3 & 19.72 & 29.38 & 154 & 22 & 67.07 & 35.32 & 52.68 \\
\hline
\end{tabular}

From (Table 1) it appears that the mean AQI as of June (2020) is lower when we compared it with 2014, 2016, 2017, 2018 and 2019; and larger when we compared it with 2015. The mean AQI as of April (2020) is lower than 2014, 2015, 2016, 2017 and 2018. Mean AQI as of May (2020) lower than other years (Table 1) [7,14,15]. The mean value of AQI June (2014-2020) was found in the category good and moderate for everyone and sensitive people. On the other hand, the mean value of AQI April (2014-2020) was found in the category of moderate, caution and unhealthy for the general people and sensitive people, and the mean value of AQI May (2014-2020) was found in the category of moderate and caution for the general people and sensitive people when it was compared with BNAAQS [16]. The mean AQI decreased 43.52 \%, $22.37 \%, 9.82 \%, 16.38 \%, 41.43$ $\%, 34.16 \%$ in April (2020) when compared with April (2014-2019) and 33.69\%, 37.97 
$\%, 39.25 \%, 36.81 \%, 45.59 \%, 44.15 \%$ in May (2020) when compared with May (20142019). The mean AQI decreased $26.48 \%, 11.40 \%, 8.28 \%, 30.61 \%, 36.37 \%$ and increased $3.07 \%$ in June (2020) when compared with (2014-2019). From Figs. (2-4), it appears that air quality in 2020 (April to June) is much better (during covid-19 situation) than in previous years. The mean value of AQI in April (2020) is to satisfy the BNAAQS limit. The mean value of AQI April (2014-2019) exceeds the limit but the mean value of May (2020) and June (2020) satisfied the BNNAQS. In some major cities of China, AQI decrease $32.2 \%, 27.7 \%, 14.9 \%$ when AQI is compared with 2017-2019 but, for Dhaka city AQI decreased 36.50\%, $22.72 \%, 21.43 \%, 21.95 \%, 40.21 \%, 38.09 \%$ when compared with 2014-2019. In Dhaka city, AQI decreases more than $12 \%$ and $23 \%$, respectively, for the years 2018 and 2019. The decrease in AQI percentage in Dhaka city for the years 2018 and 2019 is greater than in other cities [17]. Figs. 5(a-g) Illustrate the correlations and linear regression equation between days and AQI from 2014 to 2020. Value of $\mathrm{R}^{2}$ is $0.36,0.37,0.27,0.26,0.48,0.15,0.21$ respectively. It also shows negative correlations and decreasing trends with days. But 2018 shows a strong correlation than the other years.
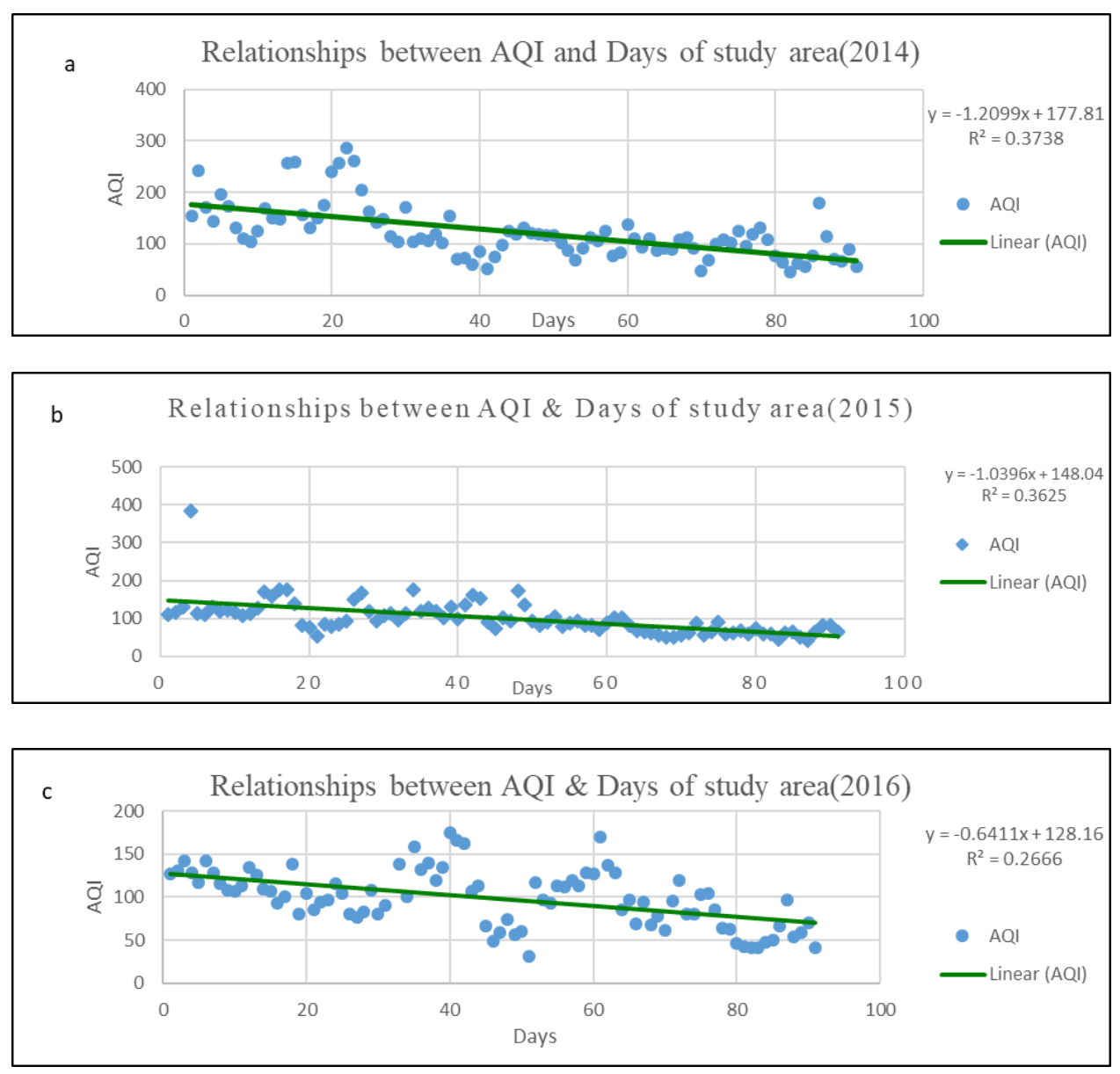

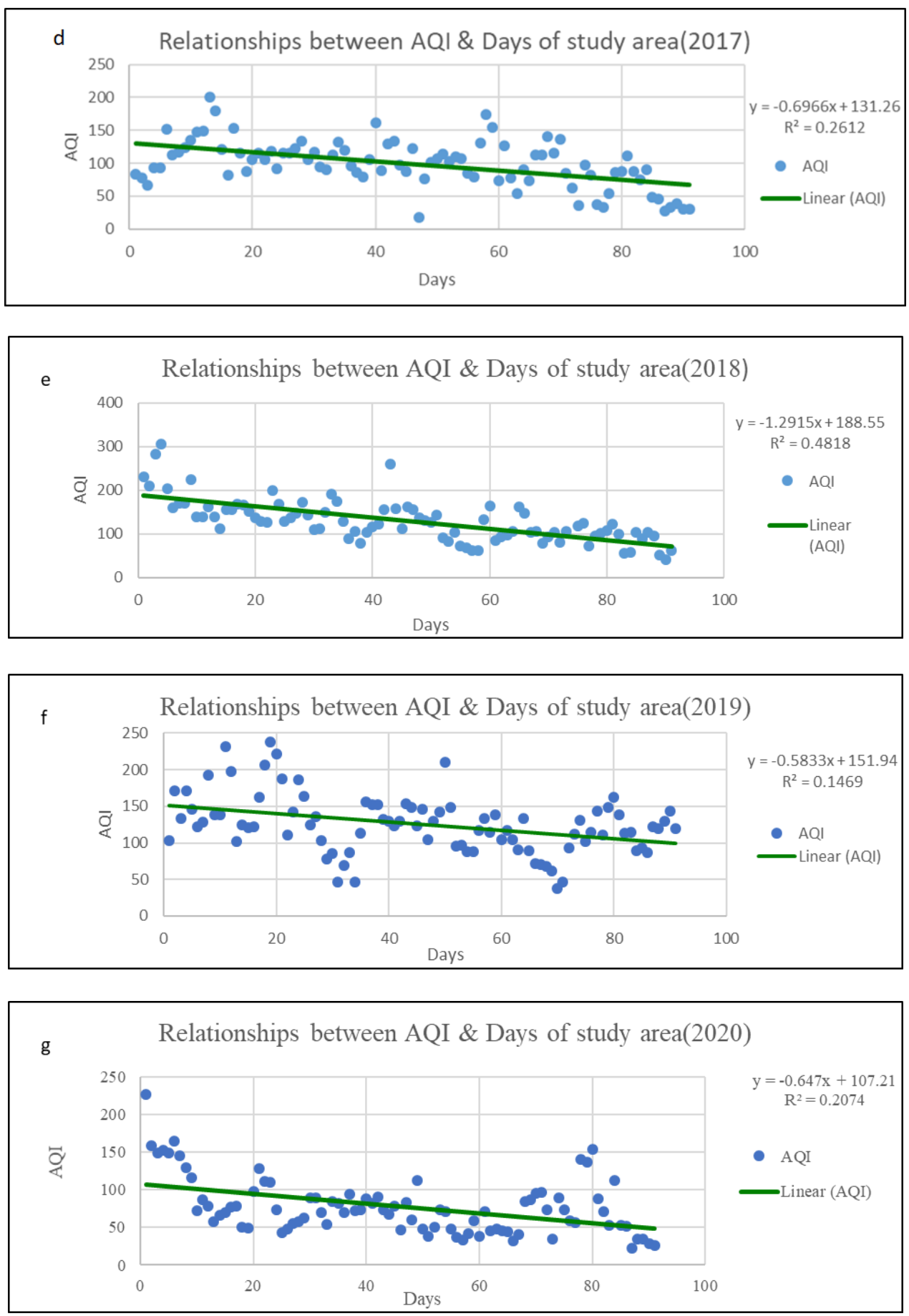

Figs. 5(a-g). Correlations and liner regression between days and AQI; (a) 2014, (b) 2015, (c) 2016, (d) 2017, (e) 2018, (f) 2019, (g) 2020. 


\section{Conclusion}

Due to the coronavirus, millions of people have died worldwide. Air pollution in Dhaka city is now a major concern because it is seriously affecting lives and has become a health issue. Our study shows that due to the covid-19 lockdown, air quality in Dhaka city has improved during the last few years when Dhaka city was marked as the most polluted city in the world. The government and policymakers of Bangladesh should take long-term strategies to decrease environmental pollution through environmentally friendly activities. Our study is only based on one parameter. However, air pollution depends on many other parameters, but we cannot use different parameters for the limitation of the fund. This secondary data could be implemented in the future for more studies.

\section{Acknowledgment}

All authors gratefully acknowledge Z. Sultana, Department of Environmental Science and Disaster Management, Bangabandhu Sheikh Mujibur Rahman Science and Technology University-8100, Gopalganj, Bangladesh, for guidelines and instructions.

\section{References}

1. M. H. Masum and S. K. Pal, Glob. J. Environ. Sci. Manag. 6, 85 (2020).

2. WHO (2016). https://www.who.int/airpollution/data/cities-2016/en/

3. WHO (2018). https://www.who.int/airpollution/data/cities/en/ (accessed Aug. 19, 2020).

4. WHO (Air Pollution). https://www.who.int/health-topics/air-pollution\#tab=tab_1 (accessed Aug. 19, 2020).

5. S. Ahmed and I. Mahmood, J. Public Admin. Policy Res. 3, 129 (2011).

6. Dhaka District-Banglapedia, http://en.banglapedia.org/index.php?title=Dhaka_District (accessed Aug. 14, 2020).

7. S. Roy, N. Chowdhury, M. Mamun, and M. Bhuyan, J. Environ. Pollut. Hum. Heal. 8, 55 (2020).

8. N. L. A. Rani, A. Azid, S. I. Khalit, H. Juahir, and M. S. Samsudin, Polish J. Environ. Study 27, 801 (2018). https://doi.org/10.15244/pjoes/75964

9. CASE, AQI Archives, http://case.doe.gov.bd/index.php?option=com_content \&view=category $\&$ id=8\&Itemid=32 (accessed Jul. 11, 2020).

10. Y. Zhu, J. Xie, F. Huang, and L. Cao, Sci. Total Environ. 727, ID 138704 (2020). https://doi.org/10.1016/j.scitotenv.2020.138704

11. S. Sharma, M. Zhang, Anshika, J. Gao, H. Zhang, and S. H. Kota, Sci. Total Environ. 728, ID 138878 (2020). https://doi.org/10.1016/j.scitotenv.2020.138878

12. G. Sarella and M. D. A. K Khambete, Int. J. Innov. Res. Sci. Technol. 1, 68 (2015).

13. K. D. Kanniah, N. A. F. Kamarul Zaman, D. G. Kaskaoutis, and M. T. Latif, Sci. Total Environ. 736, ID 139658 (2020). https://doi.org/10.1016/j.scitotenv.2020.139658

14. M. H. Rahman and A. Al-Muyeed, WIT Trans. Ecol. Environ. 82, 1743 (2016).

15. S. Nigam, B. P. S. Rao, N. Kumar, and V. A. Mhaisalkar, Res. J. Eng. Technol. 6, 267 (2015). https://doi.org/10.5958/2321-581X.2015.00041.0

16. CASE, Air Quality Index (AQI), http://case.doe.gov.bd/index.php?option=com_content \&view=article\&id=9\&Itemid=31 (accessed Oct. 11, 2020). 


\section{Covid-19 Lockdown and Changes of Air Quality}

17. K. Xu, K. Cui1, L. Young, Y. Hsieh, Y. Wang, J. Zhang, and S. Wan, Aerosol and Air Quality Res. 20, 915 (2020). https://doi.org/10.4209/aaqr.2020.04.0150 